\title{
DOI: https://doi.org/10.24297/jssr.v14i0.8415
}

\section{Community Psychology Perspective on Ecological Issues: Based on Psychological Intervention}

\author{
Aida Mehrad \\ Universitat Autònoma de Barcelona, Bellaterra, Spain \\ Department of Basic, Developmental and Educational Psychology \\ mehrad.aida@gmail.com
}

\begin{abstract}
The purpose of the current literature review is to clarify the important role of community psychology regarding ecological issues and illustrated its critical function based on psychological intervention. The results of this investigation explained that community psychology, as one of the essential fields of psychology, has substantial involvement on ecological issues and it can examine these issues based on psychological intervention. In truth, these ecological issues that some of them explained in this study (child maltreatment, drug addiction, school dropping out, and teen pregnancy) have been examined based on the psychological aspect for finding best solution way from the side of expert psychologists and counselors. Consequently, this research focused on teenagers that face with community issue via different ways, and should be considered by parents, schools, society, and government in every community and country; otherwise, it will appear any inconvenient behaviors and reactions amongst teenagers.
\end{abstract}

Keywords: Child Maltreatment, Community Psychology, Drug Addiction, Ecological Factors, School Dropping Out, Society, Teen Pregnancy

\section{Introduction}

One of the imperative approaches in the psychological area is community psychology which referred to individuals' contexts within communities and their communication with other people in society. Truly, in the community psychology tries to find the quality of individuals' life, and study individuals' behavior and reactions in their social life spatially at an unsatisfactory situation (Long \& Perkins, 2007). Furthermore, community psychology assumed as a branch discipline within psychology which explained how individuals related to the society and illustrate various behaviors and reactions at the environment (Goodkind \& LaNoue, 2012). In most of the time, community psychology studies on abnormal and violent behavior which occur in society, and it has intervention and prevention for that social system. Community psychology has some similarities with other fields in psychology. These fields are cross-cultural psychology, sociology, and social psychology. But in some cases, the concept or view of these fields about one issue is different. One of the main items that make unique community psychology toward another field is, deeply focuses on solving a problem and improving individuals' lifestyles and society as a normal form. However, each of these fields' surveys individuals' situations in various forms (Lee, 2012; Allen, Larsen, Trotter, \& Sullivan, 2013).

In actual fact, community psychology focuses on any kind of normal or abnormal behavior and actions which appear in society and try to solve or guide the community in an accurate way. And usually, it focuses on to problem in deductive form and solves them in totally form (Campbell, \& Murray, 2004; Howarth, 2007). This field of psychology does attention to society generally by interventions and preventions on the social system. Therefore, encourage community for improving and well-being (Graham, \& Haidt, 2010). Community psychology has been defined as the main link between individuals and various groups in society. This branch of psychology refers to individuals, their attitudes, believes, and performances within a social context. In actual fact, community psychology mentions about a background view of individuals and their psychology. In contrast, it investigates about individuals; kind of their living, their relationship with others, their perception about society 
and their reactions among various groups (McMillan \& Chavis, 1986). Based on Scileppi, Teed, and Torres (2000), community psychology displayed as an approach for responding to the fustigation against typical psychology. In truth, the community psychology offerings a transitional outline that sign a change toward an innovative sample. This outline generates practitioners with a theoretic base for offering a vast range of health services in society (Naiedoo, 2000). In addition, community psychology focuses on individuals' difficulties around homeless individual's family and non-family provision systems, native residents towards homeless individuals, the performs in the direction of homelessness of the local police, local facilities and whether they include or exclude those who are displaced, the availability of engagement of different kinds and conditions in the local area, national believes towards homelessness, administration policy regarding the obtainability of community welfare benefits, and worldwide and national trends in the association between capital and labor (Orford, 2008). In fact, community psychology tries to combine society or social system with individuals or a community of well-being. This branch of psychology needs to have evidence for research and solving a problem in society. Basically, community psychology concerned about the relationship between the social system and individual well-being in the community context. In addition, the community psychology attention to a social and mental health problem which appear in public and private life (Dalton, Elias, \& Wandersman, 2001). The community psychology likewise applies several views psychology to address problems of societies, the relations in the interior of them and individuals' attitudes and behavior toward their private and social life (Chavis, Hogge, McMillan \& Wandersman, 1986). Furthermore, this branch of psychology emphasizes applied and theory based. Also, it focuses on the multi-level of individuals and groups to specific programs and manages them in the community. This social view covers a broad range of setting and substantive areas (Hill \& Thomas, 2011). Based on various descriptions which mentioned about community psychology in above sentences; we can say this field of psychology needs to have widespread collaboration with other fields in psychology. Community psychology in fact drives from social psychology, social work, society and individual well-being, mental health in the social environment, etc. In this line, community psychologists concern to: promote individuals in society, provide appropriate styles of intervention when they desired to do some affairs, and enable individuals for growth their ability whereas they have problems in their life (Douglas, Hughey, \& Speer, 2002; Orford, 2008). Because of the important role of community psychology and its relationship with individuals personal and social life; in continue, focused more on this fact and examined the influence of this approach on community problems.

\section{Influence of Community Psychology Perspective on Community Issues}

Community psychology offers a powerful framework among individuals and society which usually by this framework examines groups of people which face with risk, difficulties, and in some cases abnormal reactions such as hurt or threat to themselves and others. On the other hand, this framework attention to others who are trying to help people (for solving their problems). This framework emphasizes on unite other methods and fields related to psychology for finding and solving problems. In some cases, sharing effective information of these fields to obtain the desired results. Framework in community psychology illustrates culture, structure, and relation in every society. With this method, the framework highlights positive or negative current evidence. In addition, the framework attention to values, language, and critical systems analysis to examine any kinds of abnormality based on them. In this regard, some psychologists tried to develop a framework according to scientific assessment for resolving internal and external difficulties among individuals and groups (Orford, 2008). In other words, the framework in community psychology explains the influence of useful and damages elements on individuals, and it determines prevention and intervention factors. In some cases, at the same time framework specifies the location, experiences of individuals, nationality, relation with others, etc. for finding the main issue in the community. A valuable framework in community psychology applies prevention, change, intervention, indigenous resources, citizen participation, sharing power, social justice, sense of community, level of analysis, radiating effects, and empirical grounding. Usually, the framework creates a schema for finding different levels of difficulties which people and social contact with them and the ways that by them can control and reject these problems. For these methods, there are some policies which show in community psychology's framework, and community psychologists follow them in the correct way (Chavis et al., 1986; Dalton et al., 2001). 


\section{Role of Ecological Factors on the Existence of Community Issues}

Ecological factors have been described as the relationship between organisms and their environment. These factors are a branch of sociology that focuses on the relation between groups of human and their physical and social situation and called human ecology (Mayr, 1947; Lawton, 1989). According to the role of ecological factors in community psychology, Kelly (1979) has been mentioned four principles about it. The principles included: a) interdependence (all the present systems are multiple), b) cycling of resources (systems apply resources), c) adaptation (measuring the person environments fit), and d) succession (schema can change influence the other three principles). Based on these principles, the ecological factors have been determined by some relationships and interactions between individuals and the environment. According to ecological factors can mention that these factors provide a framework for any kinds of issues in society. Furthermore, Ecological factors contribute to existing problems in society which in continue explain about some of them, comprehensively.

\section{Child Maltreatment}

Child maltreatment assumed as one of the aggressive behaviors which occur in society. Usually, this kind of behaviors appears in a lower social class. Ecological factors examine these difficulties with children's reactions and characteristics. A conceptual framework illustrates the presence of conflicts among children is a socialpsychological phenomenon. This conflict combined forces at work, the family, community, and the culture which ecological factors try to find enough condition for child maltreatment and reduce it (Belsky, 1980). According to ecological factors contribution, child maltreatment occurs in different ages among children and lots of internal and external items effect on it. Based on recent studies about child maltreatment, ecological factors focus on socioeconomic, culture and contextual factors which included individual (parenting abilities, or whether the individual obligating abuse was battered himself or herself as a kid); the micro-system (marital consistency); systems mediating between individual, family, and society (instinctive job loss, work stress, neighborhood isolation); and finally the macro-system (the level of violence in society, social norms sanctioning corporal punishment) to find main problems in child maltreatment and create sufficient situation for solving it (Orford, 2008).

\section{Teen Pregnancy}

Teen pregnancy is a social pathology that approximately occurs between $15-19$ years, and it can lead to various difficulties for individual and society. Thus, ecological factors try to discover the main reasons of this abnormal behavior (Allen et al., 1997). Presence of targeted primary prevention programs in society can control and decrease this social pathology among teenagers. In addition, ecological factors can provide enough field for growing teens' ability and direct their desire in correct ways. And these factors can mention results of this abnormality in society and design a clear schema for teenagers (Orford, 2008).

\section{Drug Addiction}

Drug addiction is another social pathology which has a direct relation with the unemployment rate, labor market outcomes, early sexual activity and pregnancy (Oetting \& Beauvais, 1990). Due to these causes, ecological factors provide favorable conditions for individuals and the community. Thereby, these two groups (individuals and community) learned more about this abnormal phenomenon and become aware of the future of this social path. In addition, ecological factors determined policy for addiction people and illustrate them the devastating consequences on individuals and the community (Orford, 2008).

\section{School Dropping Out}

School dropping is one of abnormal behavior that usually occurs between adolescence and effected by sex, race, family background, drug, etc. (Ellickson, Bui, Bell, \& McGuigan, 1998). Most of the students mentioned some main reasons for leaving school, for example; women leave the study and school just because of pregnancy or in some cases for marriage and men trend to leave school for going to work and family background 
(Rumberger, 1983; Rumberger, 1995). There are different interventions about school dropping that offer by community psychologists and government. Most of them follow policies set in the community. In this line, the involvements hired with the greatest frequency in the investigations reviewed emphasized academic improvement, psychosocial ability growth, mentoring, and parental/teacher behavior management preparation. Totally, there is not any best practice or helpful treatment presently obtainable to address the difficulties of school dropout even supposing numerous intervention agendas appear to hold promise. Suggestions for school psychologists comprise equally practice and investigation applications (Prevatt \& Kelly, 2003). In general, one of the efficient interventions about school dropping is informed students and their parents about schoolwork which lead to correct decision making. In addition, mention the benefits of study and their future work in society, this information opens a new view for students and their parents, and they start correcting the course of study. Following this effective intervention, creating optimistic school believe (additional likely to like school, to accept as true that success at school was significant, and to feel accomplished of succeeding in school) can be helpful for this efficient intervention (Orford, 2008).

\section{Conclusion}

Presence of ecological issues such as child maltreatment, drug addiction, school dropping out, and teen pregnancy possibly has been occurred in any community amongst teenagers; so, recognizing them and finding accurate solution way based on scientific and academic knowledge from parents, schools, society, government, and expert psychologists can be super helpful and effective. In this case, the main role of these mentioned groups is better realizing and applying practical methods. This literature review shows the important role of community psychology that focuses on ecological issues and explore them based on psychological intervention. The supportive groups specifically parent and schools should pay more attention to these types of issues that can be threatening for society and teenagers; also destroying their future. Applying scientific and psychological ways from side of psychologists to improving and conducting teenagers by organizing some workshops or seminars can be efficient.

\section{Reference}

1. Allen, N. E., Larsen, S., Trotter, J., \& Sullivan, C. M. (2013). Exploring the core service delivery processes of evidence-based community advocacy program for women with abuse partner, Journal of community psychology, 41(1), 1-18.

2. Belsky, J. (1980). Child maltreatment: an ecological integration. American Psychologist, 35(4), 320-335.

3. Campbell, C., \& Murray, M. (2004). Community health psychology promoting analysis and action for social change. Journal of health psychology, 9(2), 187-195.

4. Chavis, D. M., Hogge, J. H., McMillan, D. W., \& Wandersman, A. (1986). Sense of community through Brunswik's lens: A first look. Journal of community psychology, 14(1), 24-40.

5. Dalton, J. H., Elias, M. J., \& Wandersman, A. (2001). Community Psychology: Linking Individuals and Communities. Stamford, CT: Wadsworth.

6. Douglas, D. P., Hughey, J., \& Speer, P.W. (2002). Community psychology perspectives on social capital theory and community development practice. Journal of the Community Development Society, 33 (1),33-52.

7. Ellickson, P., Bui, K., Bell, R., \& McGuigan, K. A. (1998). Does early drug use increase the risk of dropping out of high school? Journal of Drug Issues, 28, 357-380.

8. Goodkind, J., \& LaNoue, M. (2012). Feasibility, acceptability and initial findings from a community-based culture mental health intervention for American Indian youth and their families. Journal of community psychology,40 (4), 381-405. 
9. Graham, J., \& Haidt, J. (2010). Beyond Beliefs: Religions Bind Individuals into Moral Communities. Journal of personality and social psychology review, 14 (1),140-150.

10. Hill, J., \& Thomas, E. (2011). Community psychology: Linking individuals and communities. Cengage Learning.

11. Howarth, C., S. (2007). Towards a Social Psychology of Community: A Social Representations Perspective. Journal of social behavior, 31 (2), 223-238.

12. Kelly, J. G. (1979). Taint what you do, it's the way you do it. American Journal of Community Psychology, 7, 244-258.

13. Lawton, M. P. (1989). Behavior-relevant ecological factors. Social structure and aging: Psychological processes, 57-78.

14. Lee, M. (2012). Community violence exposure and adolescence substance use does monitoring and positive parenting moderate risk in urban communities? Journal of Community Psychology,40 (4), 406-421.

15. Long, D. A., \& Perkins, D. D. (2007). Community social and place predictors of sense of community: A multilevel and longitudinal analysis. Journal of community psychology, 35(5), 563-581.

16. Mayr, E. (1947). Ecological factors in speciation. Evolution, 263-288.

17. McMillan, D. W., \& Chavis, D. M. (1986). Sense of community: A definition and theory. Journal of community psychology, 14(1), 6-23.

18. Naiedoo, A. V. (2000). Community psychology: Constructing community, reconstructing psychology in South Africa. Inaugural Lecture. University of Stellenbosch.

19. Oetting, E. R., \& Beauvais, F. (1990). Adolescent drug use: Findings of national and local surveys. Journal of Consulting and Clinical Psychology, 58(4), 385-394.

20. Orford, J. (2008). Community psychology: Challenges, controversies, and emerging consensus. Wiley

21. Prevatt, F., \& Kelly, F. D. (2003). Dropping out of school: A review of intervention programs. Journal of school psychology, 41(5), 377-395.

22. Rumberger, R. W. (1983). Dropping out of high school: The influence of race, sex, and family background. American Educational Research Journal, 20(2), 199-220.

23. Rumberger, R. W. (1995). Dropping out of middle school: A multilevel analysis of students and schools. American educational Research journal, 32(3), 583-625.

24. Scileppi, J. A., Teed, E. L., \& Torres, R. D. (2000). Community Psychology: A common-sense approach to mental health. New Jersey: Prentice-Hall 